\title{
Metastatic screening for patients with newly diagnosed breast cancer: Who and how?
}

\begin{tabular}{|c|c|}
\hline $\begin{array}{l}\text { Authors: } \\
\text { Jenny Edge }{ }^{1} \\
\text { Melissa Budge } \\
\text { Adiel Webner }^{1} \\
\text { Alexander Dor } \\
\text { Glen Cilliers }{ }^{3} \\
\text { Francois Malh }\end{array}$ & erbe $^{4}$ \\
\hline $\begin{array}{l}\text { Affiliations: } \\
{ }^{1} \text { Division of Su } \\
\text { Department o } \\
\text { Sciences, Facu } \\
\text { and Health Sci } \\
\text { Stellenbosch } \\
\text { Cape Town, S }\end{array}$ & $\begin{array}{l}\text { rgery, } \\
\text { f Surgical } \\
\text { Ity of Medicine } \\
\text { ences, } \\
\text { Jniversity, } \\
\text { outh Africa }\end{array}$ \\
\hline $\begin{array}{l}{ }^{2} \text { Division of } \mathrm{Nu} \\
\text { Medicine, Fac } \\
\text { Medicine and } \\
\text { Sciences, Stell } \\
\text { University, Car } \\
\text { South Africa }\end{array}$ & $\begin{array}{l}\text { ultear of } \\
\text { Health } \\
\text { enbosch } \\
\text { e Town, }\end{array}$ \\
\hline $\begin{array}{l}{ }^{3} \text { Morton and } \mathrm{P} \\
\text { Radiologists, } \\
\text { South Africa }\end{array}$ & $\begin{array}{l}\text { artners } \\
\text { ape Town, }\end{array}$ \\
\hline $\begin{array}{l}{ }^{4} \text { Division of Su } \\
\text { of Medicine ar } \\
\text { Sciences, Univ } \\
\text { Cape Town, Ca } \\
\text { South Africa }\end{array}$ & $\begin{array}{l}\text { rgery, Faculty } \\
\text { d Health } \\
\text { ersity of } \\
\text { pe Town, }\end{array}$ \\
\hline $\begin{array}{l}\text { Correspondin } \\
\text { Jenny Edge, } \\
\text { dr@jennyedge }\end{array}$ & $\begin{array}{l}\text { g author: } \\
\text { eco.za }\end{array}$ \\
\hline $\begin{array}{l}\text { Dates: } \\
\text { Received: } 23 \mathrm{~J} \\
\text { Accepted: } 11 \\
\text { Published: } 06\end{array}$ & $\begin{array}{l}\text { ul. } 2019 \\
\text { Eeb. } 2020 \\
\text { Apr. } 2020\end{array}$ \\
\hline $\begin{array}{l}\text { How to cite th } \\
\text { Edge J, Budge } \\
\text { Doruyter A, Ci } \\
\text { Malherbe F. M } \\
\text { screening for } \\
\text { with newly dia } \\
\text { breast cancer: } \\
\text { how?. S. Afr. j. } \\
2020 ; 4(0) \text {, a94 } \\
\text { org/10.4102/s }\end{array}$ & $\begin{array}{l}\text { is article: } \\
\text { M, Webner A, } \\
\text { lliers G, } \\
\text { letastatic } \\
\text { patients } \\
\text { gnosed } \\
\text { Who and } \\
\text { oncol. } \\
\text { https://doi. } \\
\text { ajo.v4i0.94 }\end{array}$ \\
\hline Read online: & \\
\hline 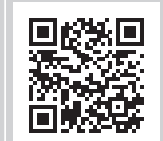 & $\begin{array}{l}\text { Scan this QR } \\
\text { code with your } \\
\text { smart phone or } \\
\text { mobile device } \\
\text { to read online. }\end{array}$ \\
\hline
\end{tabular}

Background: Staging for breast cancer patients, as defined by the American Joint Committee on Cancer (AJCC), has historically been limited to anatomical staging. However, the eighth version of the AJCC guidelines has been altered to include tumour biology. Anatomical staging still has a place especially in low-middle income countries where the majority of patients present with locally advanced or metastatic disease.

Aim: This review article considers which newly diagnosed breast cancer patients should be referred for anatomical staging and the pros and cons of the different modalities available in South Africa.

Method: The different modalities available were reviewed with respect to metastatic screening for asymptomatic women. The usefulness of the modalities were considered with reference to organ-specific disease rather than the stage of the patient.

Results: Any person with newly diagnosed breast cancer and symptoms suggestive of systemic involvement should be investigated. All symptomatic women who present with a tumour larger than $5 \mathrm{~cm}$, radiological or clinical evidence of nodal disease, triple negative or HER2+ve tumours should have metastatic screening. This gives information about the primary as well as the metastatic status.

Conclusion: However, increasingly, the major determinant of treatment is the biology of the cancer and not the anatomical stage. In future, this trend is likely to increase with anatomical staging becoming less important.

Keywords: breast cancer; metastatic disease; screening; guidelines; best practice; review.

\section{Introduction}

There are no comprehensive guidelines for metastatic screening for newly diagnosed patients in South Africa (SA), although the 2018 National Breast Health Policy (which is still to be finalised and formally adopted) will provide some guidance. This article aims to review the most recent literature and international guidelines with consideration given to best practice in SA, both in the public and private sectors.

Globally, breast cancer is the most prevalent cancer affecting women and the incidence in low-middle income countries (LMICs) is predicted to rise as life expectancy increases. ${ }^{1}$ The stage at the time of presentation differs between high-income countries (HICs) and LMICs. In the United States, between 35\% (uninsured population) and 76\% (insured population) of women, aged between 50 and 74 years, had a mammogram in the preceding 2 years. This contrasts with figures from a 2003 World Health survey where only 2.2\% women in LMICs aged 40-69 received any breast screening. ${ }^{2,3}$

While accurate statistics are not available for SA, it is estimated that between $50 \%$ and $60 \%$ of women present with locally advanced or metastatic breast cancer. ${ }^{4,5}$ This figure compares unfavourably to those from HICs (many of whom have population-based screening programmes) where approximately $5 \%$ of women present with the metastatic disease. ${ }^{6}$

Staging, as defined by the American Joint Committee on Cancer (AJCC), has historically been limited to anatomical staging. While the eighth version of the AJCC guidelines ${ }^{7}$ has been altered to include tumour biology, anatomical staging still holds a place, as it allows for population studies, provides a concise summary of the patient, gives an indication of tumour biology, permits comparative population-based studies and guides treatment. However, some controversy exists

Copyright: (C) 2020. The Authors. Licensee: AOSIS. This work is licensed under the Creative Commons Attribution License. 
with the diagnosis of metastatic disease. Traditionally, stage IV disease has been defined as incurable but not untreatable. However, because of increased definition of imaging modalities, a number of patients are diagnosed with lowvolume oligometastatic disease. Although technically classified as a stage IV disease, it may, in some instances, be curable.

\section{Who should undergo metastatic screening?}

Most guidelines agree that patients who present with symptoms that could be attributable to metastatic spread should be investigated. However, there is an ongoing debate about which asymptomatic patients should have systemic screening and what modality should be used. Overall, the detection of metastatic disease is $1 \%-16 \%{ }^{8}$ The likelihood of finding metastatic disease increases with the clinical stage at presentation and is dependent on the modality used. Six per cent of patients with clinically determined stage IIb disease are upgraded to stage IV, as are $14 \%-25 \%$ of those clinically presenting with stage III of the disease. ${ }^{6}$ The National Comprehensive Cancer Network (NCCN) and European Society of Medical Oncologists (ESMO) both recommend metastatic screening for all patients with a cancerous lesion or tumour $>5 \mathrm{~cm}$ in size and clinical or radiological nodal metastases. 9,10

There are several subgroups of patients with early breast cancer who should also be considered for metastatic screening. Patients with triple-negative disease are known to have a higher chance of visceral metastases, and some authors have suggested that patients less than 40 years should be considered separately. ${ }^{11}$

The following arguments against metastatic screening for all are well-documented:

- The cost involved.

- Oligometastatic disease (low-volume metastatic disease). As imaging modalities have become more advanced, smaller lesions are detected. The oligometastatic disease may, in some instances, be curable. Defining these women as being affected with stage IV of the disease may result in them no longer being treated with an intention to cure, thereby denying them the chance of cure. However, the detection of even low-volume metastatic disease may change the management approach.

- Anxiety to the patient and the family.

The balance between cost, availability of local resources and benefit from anatomical screening in women newly diagnosed with breast cancer continues to be debated. While international guidelines differ in specific recommendations, all agree that any symptomatic woman should have relevant metastatic screening and that there is no role for metastatic screening in asymptomatic women with early breast cancer. The National Institute for Health and Care Excellence (NICE) guidelines recommend staging for asymptomatic patients presenting with symptoms related to stage III and above but are vague regarding what modality should be used. ${ }^{12}$ This prompted a survey to be carried out by the Association of British Surgeons (ABS) asking breast care units about their practices. They found poor consistency amongst the 123 recipients as to who should be screened. Interestingly, the modalities available were chest X-ray (CXR) (99\%), computed tomography (CT) scan (99\%), magnetic resonance imaging (MRI) (95\%), liver ultrasound (US) (100\%), bone scan (10\%) and positron emission tomographyCT (PET-CT) scan $(57 \%) .^{13}$

\section{What modalities should be used for screening?}

The different modalities available will be reviewed with respect to metastatic screening for asymptomatic women. The usefulness of the modalities will be considered with reference to organ-specific disease rather than the stage of the patient.

\section{Chest X-ray}

The lung is not a common site of metastatic disease detected with CXR. According to the pooled prevalence in studies performed after 1998, 25/2258 patients (1.1\%) had lung metastases (Table 1). Only two studies have reported CXR results by stage of the disease. ${ }^{8,14}$ Data were collected retrospectively in both studies. A CXR was performed before surgery in one study and after surgery in the other. ${ }^{15}$ The pooled prevalence of distant metastases in stage I of the disease was $0.1 \%$ and $1.7 \%$ in stage III of the disease, with an overall prevalence of $0.5 \%$. Barret et al. ${ }^{16}$ stated that preoperative CXR is not used as a staging investigation, and this recommendation is supported by the latest ESMO guidelines. ${ }^{10}$

\section{Bone scan}

The bone scan is commonly used for detecting bone metastases in patients with breast cancer. The detection rate of a bone scan for skeletal metastases is more sensitive than skeletal radiographs. ${ }^{20}$ Although sensitivity rates as high as $98 \%$ have been reported, ${ }^{21}$ the most recent meta-analysis investigating bone scan reported a sensitivity of $81 \%$ (95\% confidence interval [CI]: $58 \%-93 \%)$ and a specificity of $96 \%(95 \% \mathrm{CI}$ : $76 \%-100 \%){ }^{22}$ The overall pooled prevalence of bone metastases is low in studies conducted after 1998 (Table 2). The pooled prevalence of distant bone metastases was 258/10 241 (2.5\%). Similar to lung metastases, bone metastases are more common in more advanced disease. Myers et al. $^{23}$, in

TABLE 1: Prevalence of lung metastasis in all stages of disease as detected by chest X-ray.

\begin{tabular}{lccccc}
\hline Study & $\begin{array}{l}\text { Year of } \\
\text { report }\end{array}$ & $\begin{array}{c}\text { Patients in } \\
\text { study }(\boldsymbol{n})\end{array}$ & \multicolumn{3}{c}{ Lung metastasis } \\
\cline { 5 - 7 } & & & $\boldsymbol{N}$ & Total & $\%$ \\
\hline Ravaioli et al. ${ }^{17}$ & 1998 & 1218 & 8 & 1206 & 0.7 \\
Barry et al. $^{18}$ & 1999 & 82 & 1 & 79 & 1.2 \\
Dillman and Chico $^{8}$ & 2000 & 947 & 12 & 545 & 2.2 \\
Puglisi et al. ${ }^{19}$ & 2005 & 412 & 4 & 428 & 0.9 \\
All studies & - & - & 25 & 2258 & 1.1 \\
\hline
\end{tabular}


TABLE 2: Prevalence of bone metastasis in all stages of disease as detected by bone scan.

\begin{tabular}{|c|c|c|c|c|c|}
\hline \multirow[t]{2}{*}{ Study } & \multirow{2}{*}{$\begin{array}{l}\text { Year of } \\
\text { report }\end{array}$} & \multirow{2}{*}{$\begin{array}{l}\text { Patients in } \\
\text { study }(n)\end{array}$} & \multicolumn{3}{|c|}{ Bone metastasis } \\
\hline & & & $N$ & Total & $\%$ \\
\hline Ravaioli et al. ${ }^{17}$ & 1998 & 1218 & 37 & 1193 & 3.1 \\
\hline Dillman and $\mathrm{Chico}^{8}$ & 2000 & 947 & 20 & 601 & 3.3 \\
\hline Koizumi et al..$^{24}$ & 2001 & 5538 & 118 & 5538 & 2.1 \\
\hline Puglisi et al. ${ }^{19}$ & 2005 & 412 & 26 & 412 & 6.3 \\
\hline Lee et al. ${ }^{25}$ & 2005 & 1939 & 28 & 1939 & 1.4 \\
\hline Kasem et al. ${ }^{26}$ & 2006 & 221 & 6 & 221 & 2.7 \\
\hline Barrett et al. ${ }^{16}$ & 2009 & 2612 & 23 & 337 & 6.8 \\
\hline All studies & - & - & 258 & 10241 & 2.5 \\
\hline
\end{tabular}

their meta-analysis, reported a pooled prevalence ranging from $0.5 \%$ in stage I of the disease to $8.3 \%$ in stage III of the disease, with an overall prevalence of $3.1 \%$.

\section{Liver ultrasound}

The liver is less frequently involved than bone and liver metastases, and in asymptomatic patients, it is quite rare. Myers et al. ${ }^{23}$ reported a pooled prevalence ranging from $0 \%$ in stage I of the disease to $2 \%$ in stage III of the disease, with an overall prevalence of $0.6 \%$. The pooled prevalence in data published after 1998 was 0.9\% (23/2404) (Table 3).

\section{Computed tomography scan}

Computed tomography scan has the advantage of being fast and reliable, and it allows for the assessment of the lungs, liver and bone in a single investigation. It is the primary screening modality used in the United Kingdom. ${ }^{13}$ The limitations of CT scan are the need for adequate renal function and patients being subjected to radiation. Computed tomography scan is sensitive for the detection of lung and liver metastases $(75 \%-100 \%)$, with relatively good specificity $(91 \%-98 \%){ }^{16,27,28}$ The area of controversy for its use as a single imaging investigation for women with breast cancer has been its reliability in the detection of bone lesions. McCartan et al. ${ }^{29}$ reviewed the results of screening 631 breast cancer patients with both a bone scan and a CT scan and determined that 69 patients had metastatic disease and 39 had bone metastases. All but two of the patients with bone metastases had axial involvement, which was detected on the CT scan.

In LMICs where locally advanced breast cancer is commonplace, the question of surgical resectability is often problematic. The CT scan has the added advantage of providing good definition of the soft tissue and so provides valuable information when considering the resectability of tumours and the degree of local infiltration into the chest wall.

\section{Whole body magnetic resonance imaging screening for metastases}

Whole body MRI (WBMRI) is emerging as a valuable imaging solution to screen for metastases in cancer patients, including breast cancer. Imaging with WBMRI aims to screen for metastatic involvement of regional and distant sites. Skeletal,
TABLE 3: Prevalence of liver metastasis in all stages of disease, as detected by liver ultrasound.

\begin{tabular}{|c|c|c|c|c|c|}
\hline \multirow[t]{2}{*}{ Study } & \multirow{2}{*}{$\begin{array}{c}\text { Year } \\
\text { of report }\end{array}$} & \multirow{2}{*}{$\begin{array}{l}\text { Patients in } \\
\text { study }(n)\end{array}$} & \multicolumn{3}{|c|}{ Liver metastasis } \\
\hline & & & $\boldsymbol{N}$ & Total & $\%$ \\
\hline Ravaioli et al. ${ }^{17}$ & 1998 & 1218 & 10 & 1206 & 0.8 \\
\hline Dillman and $\mathrm{Chico}^{8}$ & 2000 & 947 & 1 & 226 & 0.4 \\
\hline Puglisi et al. ${ }^{19}$ & 2005 & 412 & 3 & 412 & 0.7 \\
\hline Kasem et al. ${ }^{26}$ & 2006 & 221 & 3 & 221 & 1.4 \\
\hline Barrett et al. ${ }^{16}$ & 2009 & 2612 & 6 & 339 & 1.8 \\
\hline All studies & - & - & 23 & 2404 & 0.9 \\
\hline
\end{tabular}

nodal, visceral and soft tissue metastases can be identified, with varying degrees of accuracy. ${ }^{30,31,32,33}$

Several studies have assessed the performance of WBMRI as a screening tool versus conventional and specialised modalities (e.g. CT, bone scintigraphy, PET, PET-CT). These studies have highlighted the favourable performance of WBMRI, certain shortcomings and accuracy spectrum depending on the anatomical site of involvement.

The protocol for WBMRI is not standardised between institutions, and this has a significant effect on the results of trials and meta-analyses. Whole body MRI can be performed only as diffusion-weighted whole body imaging with background body signal suppression (DWIBS) or with additional sequences (T1, STIR short tau inversion-recovery.

T1, other). Specialised coils can further improve performance accuracy and affect trial results. At our institution (i.e. Morton and Partners Radiologists), the study involves whole body DWIBS, whole body T1 and STIR, and dedicated spinal T1 and STIR.

Whole body MRI is a highly accurate modality for the detection of skeletal metastases, equalling or outperforming bone scintigraphy, fluorodeoxyglucose (FDG) PET and PET-CT, with sensitivity and specificity above $90 \% .^{29,30}$ For liver metastases, WBMRI has comparable performance with CT (sensitivity of $92 \%$ and specificity of $87 \%$, vs. $93 \%$ and $96 \%$ for CT). ${ }^{32,33}$ When screening for nodal metastases, the accuracy is similar or slightly lower, compared with PET-CT and contrasted CT (accuracy $87 \%$ vs. 95\%). ${ }^{31,32}$ Lung metastases screening using only diffusion (DWIBS) is inadequate, with high specificity (91\%) but only $33 \%$ sensitivity (accuracy 61\%). ${ }^{32}$ With dedicated coils and further sequences, the sensitivity can be increased to $86 \%$ for $6 \mathrm{~mm}-9 \mathrm{~mm}$ lesions and $100 \%$ for $>10 \mathrm{~mm}$ lesions. ${ }^{34}$

The advantages of WBMRI are as follows:

- True whole-body imaging (including the brain).

- Comparable or better than conventional modalities for bone and liver metastases.

- No radiation or intravenous contrast injection.

- Readily available and cost-effective (especially when compared with PET-CT). 
The disadvantages include lower sensitivity for lung metastases, especially small lesions, and lower accuracy for nodal metastases when compared with PET-CT.

Breast cancer histo-molecular subtype characteristics can further impact on and personalise the future approach to metastatic screening. Skeletal metastases are by far the predominant site in luminal $\mathrm{A}$ and $\mathrm{B}$ tumours and the predominant site in Her2+/Hormone Receptor (HR)+, Her2+/HR- and triple-negative (TN) non-basal subgroups. Visceral and nodal metastases are more prevalent in TN, basal-like tumours. These differences may well impact decisions pertaining to preferred imaging modality.

Taking accuracy at various metastatic sites and tumour histomolecular characteristics into account, the role of WBMRI may be:

- Additional to baseline anatomical screening or CT to allow future follow-up and problem-solving.

- Assessing the treatment response of systemic disease.

- Follow-up in cancer subtypes at high risk of predominantly skeletal metastases.

\section{Fluorine-18 fluorodeoxyglucose positron emission tomography-computed tomography}

Positron emission tomography combined with sequential (X-ray) computed tomography (PET-CT) is most commonly performed using fluorine-18 fluorodeoxyglucose ([F-18]-FDG), a glucose analogue. Because many cancers, including most breast cancers, avidly metabolise glucose, FDG PET-CT offers a sensitive means to detect malignant tissue. Accumulating evidence has recently led to the societal endorsement of FDG PET-CT as an alternative to CT and bone scan for the baseline staging of advanced breast cancer. ${ }^{35}$

There is evidence that PET-CT is similarly specific but more sensitive than bone scan in the detection of skeletal metastases (sensitivity: 93\% [82\% - 98\%] vs. 81\% [58\% - 93\%]; specificity: $99 \%[95 \%-100 \%]$ vs. $96 \%[76 \%-100 \%])^{22}$ and more sensitive than diagnostic CT (chest-abdomen-pelvis) in the detection of distant metastatic spread to all sites combined (odds ratio [OR] 3.28 [92.37-4.53]). ${ }^{36}$ There is also support for PET-CT's superior sensitivity (and similar specificity), compared to other conventional imaging strategies that combine techniques such as CXR or chest CT, and liver ultrasound. In a meta-analysis analysing six such comparative studies (total of 664 patients), PET-CT was found to be similarly specific but more sensitive than conventional imaging in identifying metastases to all sites combined (sensitivity: $97 \%$ [84\% - 99\%] vs. 56\% [38\% - 74\%]; specificity: 95\% [93\% - 97\%] vs. $91 \%[78 \%-97 \%]) .{ }^{37}$ Positron emission tomographycomputed tomography has also been better studied than WBMRI, for which evidence in breast cancer staging, although promising, is more limited.

Advantages of FDG PET-CT include the fact that it can frequently replace staging strategies that rely on multiple imaging tests, that it offers whole body assessment and that it is relatively straightforward (and rapid) to interpret. Disadvantages of PET-CT include its limited availability, high cost and an ionising radiation burden similar in magnitude to standalone contrast-enhanced CT chestabdomen. Additional drawbacks of PET, such as its relatively limited spatial resolution and its lower sensitivity in lobular carcinoma subtype because of reduced FDG-avidity, are partially mitigated by information obtained from the sequentially acquired CT component of the PET-CT.

\section{Recommendations for positron emission tomography scan in breast cancer}

\section{Early stage}

Not recommended as routine for locoregional (early) disease. ${ }^{38}$

Not recommended as routine in patients presenting with clinical stage I, II or operable stage III disease symptoms. ${ }^{39}$

\section{Late stage}

May be considered instead of, and not in addition to, bone scan and diagnostic CT in patients with locally advanced disease* (level IIB recommendation). ${ }^{35}$ Positron emission tomographycomputed tomography does not replace sentinel lymph node biopsy and axillary node dissection. ${ }^{38}$

May be considered when conventional imaging is inconclusive in patients with locally advanced disease ${ }^{* 1}$, in tumours with aggressive biology or in cases of suspected metastatic disease (on the basis of signs, symptoms or laboratory values)..$^{38,39,40,41}$

May be considered in addition to bone scan and diagnostic $C T$ in patients presenting with clinical stage IIIa (T3N1M0) of the disease and for staging of high-risk patients who are candidates for neoadjuvant chemotherapy. ${ }^{39}$ Positron emission tomography-computed tomography obviates bone scan if skeletal metastases are identified. ${ }^{39}$

\section{Conclusion}

Any person with newly diagnosed breast cancer and symptoms suggestive of systemic involvement should be investigated. All symptomatic women who present with a tumour larger than $5 \mathrm{~cm}$, radiological or clinical evidence of nodal disease, triple negative or HER2+ve tumours should have metastatic screening. Whilst the modality utilised may vary with local availability, the recommendations of the authors is for a CT scan of the chest and abdomen. This gives information about the primary as well as the metastatic status. Although routine bone scan is not recommended if a CT scan is done, a bone scan can be added selectively if the patient complains of symptoms suspicious of bone metastases with a normal CT scan and no other pathology to explain the symptoms. The other indication for a bone

\footnotetext{
*. Where locally advanced breast cancer is defined by cases with any of the following large tumours ( $>5 \mathrm{~cm}$ in diameter); tumours that involve overlying skin or underlying
muscle; involvement of multiple regional lymph nodes; or inflammatory breast muscle;
} 
scan would be an inconclusive CT scan where the reporting radiologist is unsure if the bone pathology seen represents metastases. The decreasing cost of newer modalities of screening, such as PET-CT scan and WBMRI, makes these modalities increasingly accessible, and the majority of recent publications on the subject of metastatic screening have assessed their utilisation. However, increasingly, the major determinant of treatment is the biology of the cancer and not the anatomical stage. In future, this trend is likely to increase with anatomical staging becoming less important.

\section{Acknowledgements}

This article was based on a discussion held at the Cape Town Breast Forum in February 2019.

\section{Competing interests}

The authors have declared that no competing interests exist.

\section{Authors' contributions}

All authors contributed equally to this work.

\section{Ethical considerations}

This article followed all ethical standards for a research without direct contact with human or animal subjects.'

\section{Funding information}

This research received no specific grant from any funding agency in the public, commercial or not-for-profit sectors.

\section{Data availability statement}

Data sharing is not applicable to this article as no new data were created or analysed in this study.

\section{Disclaimer}

The views and opinions expressed in this article are those of the authors and do not necessarily reflect the official policy or position of any affiliated agency of the authors.

\section{References}

1. Bray F. Transitions in human development and the global cancer burden. In: Wild CP, Stewart B, editors. World cancer report 2014. Lyon: International Agency for Research on Cancer; 2014;54-68.

2. Akinyemiju TF. Socio-economic and health access determinants of breast and cervical cancer screening in low-income countries: Analysis of the World Health Survey. PLoS One. 2012;7(11):e48834. https://doi.org/10.1371/journal.pone.0048834

3. Editorial, Breast cancer in developing countries. Vol. 374. thelancet.com; 2009.

4. Cubasch $H$, Joffe $M$, Hanisch $R$, et al. Breast cancer characteristics and HIV among 1,092 women in Soweto, South Africa. Breast Cancer Res Treat. 2013;140(1):177-186. https://doi.org/10.1007/s10549-013-2606-y

5. McKenzie F, Zietsman A, Galukande M, et al. Drivers of advanced stage at breast cancer diagnosis in the multicountry African breast cancer - Disparities in outcomes (ABC-DO) study. Int J Cancer. 2018;142(8):1568-1579. https://doi. org/10.1002/ijc.31187

6. Cancer Research UK. Breast cancer incidence statistics [homepage on the Internet]. [cited 2020 Jan 20]. Available from: https://www.cancerresearchuk. org/health-professional/cancer-statistics/incidence
7. Giuliano $A E$, Edge $S B$, Hortobagyi GN. Eighth edition of the AJCC cancer staging manual: Breast cancer. Ann Surg Oncol. 2018:25(7):1783-1785. https://doi. manual: Breast cancer. Ann Sur
org/10.1245/s10434-018-6486-6

8. Dillman RO, Chico S. Radiological tests after a new diagnosis of breast cancer. Eff Clin Pract. 2000;3(1):1-6. PMID: 10788031

9. National Comprehensive Cancer Network. NCCM clinical practice guidelines in oncology, version 1 [homepage on the Internet]. 2019 [cited 2019 Jul 11]. Available from: https://www.nccn.org/professionals/physician_gls/recently_updated.aspx

10. Senkus E, Kyriakides S, Ohno S, et al. Primary breast Cancer: ESMO clinical practice guidelines for diagnosis, treatment and follow-up. Ann Oncol. 2015;26(suppl 5):v8-v30. https://doi.org/10.1093/annonc/mdv298

11. Reidl CC, Slobod E, Jochelson M, et al. Retrospective analysis of ${ }^{18}$ FDG PET/CT for staging asymptomatic breast cancer patients younger than 40 years. J Nucl Med. staging asymptomatic breast cancer patients younger than 40 years. J
2014;55(10):1578-1583. https://doi.org/10.2967/jnumed.114.143297

12. National Institute for Health and Care Excellence. NICE guidance [homepage on the Internet] [cited $2019 \mathrm{Jul}$ 11]. Available from: https://www.nice.org.uk/guidance

13. Chand N, Cutress RI, Oeppen RS, Agrawal A. Staging investigations in breast cancer: Collective opinion of UK breast surgeons. Int J Breast Cancer. 2013; Art\#. 506172. https://doi.org/10.1155/2013/506172

14. Brennan ME, Houssami N. Evaluation of the evidence on staging imaging for detection of asymptomatic distant metastases in newly diagnosed breast cancer Breast. 2012;21(2):112-123. https://doi.org/10.1016/j.breast.2011.10.005

15. Glynne-Jones R, Young T, Ahmed A, Ell PJ, Berry RJ. How far investigations for occult metastases in breast cancer aid the clinician. Clin Oncol. 1991;3(2):65-72. PMID: 2031885. https://doi.org/10.1016/S0936-6555(05)81165-3

16. Barrett T, Bowden DJ, Greenberg DC, Brown CH, Wishart, GC, Britton PD. Radiological staging in breast cancer: which asymptomatic patients to image and Radiological staging in breast cancer: which asymptomatic patients to image and
how. Br J Cancer. 2009;101(9):1522-1528. https://doi.org/10.1038/sj.bjc.6605323

17. Ravaioli A, Tassinari D, Pasini G, et al. Staging of breast cancer: What standards should be used in research and clinical practice? Ann Oncol. 1998;9(11):1173-1177. https://doi.org/10.1023/a:1008483806113

18. Barry MC, Thornton F, Murphy M, Younis F, Watson RG. The value of metastatic screening in early primary breast cancer. Ir J Med Sci. 1999;168(4):248-250. PMID: 10624363. https://doi.org/10.1007/BF02944350

19. Puglisi F, Follador A, Minisini AM, et al. Baseline staging tests after a new diagnosis of breast cancer: Further evidence of their limited indications. Ann Oncol. 2005;16(2):263-266. https://doi.org/10.1093/annonc/mdi063

20. Yeh KA, Fortunato L, Ridge JA, Hoffman JP, Eisenberg BL, Sigurdson ER. Routine bone scanning in patients with $\mathrm{T} 1$ and $\mathrm{T} 2$ breast cancer: A waste of money. Ann Surg Oncol.1995;2(4):319-324. PMID: 7552621. https://doi.org/10.1007/ BF02307064

21. Crippa F, Seregni E, Agresti R, Bombardieri E, Buraggi GL. Bone scintigraphy in breast cancer: A ten-year follow-up study. J Nucl Biol Med. 1993;37(2):57-61. PMID: 8373834

22. Rong J, Wang S, Ding Q, Yun M, Zheng Z, Ye S. Comparison of 18FDG PET-CT and bone scintigraphy for detection of bone metastases in breast cancer patients. A meta-analysis. Surg Oncol. 2013;22(2):86-91. https://doi.org/10.1016/j. suronc.2013.01.002

23. Myers RE, Johnston $M$, Pritchard $K$, Levine $M$, Oliver T. Baseline staging tests in primary breast cancer: A practice guideline. CMAJ. 2001;164(10):1439-1444. PMID: 11387916

24. Koizumi M, Yoshimoto $M$, Kasumi F, Ogata E. What do breast cancer patients benefit from staging bone scintigraphy? Jpn J Clin Oncol. 2001;31(6):263-269. https://doi.org/10.1093/jjco/hye049

25. Lee JE, Park SS, Han W, et al. The clinical use of staging bone scan in patients with breast carcinoma: Reevaluation by the 2003 American Joint Committee on cancer staging system. Cancer. 2005;104(3):499-503. https://doi.org/10.1002/cncr.21200

26. Kasem AR, Desai A, Daniell S, Sinha P. Bone scan and liver ultrasound scan in the preoperative staging for primary breast cancer. Breast J. 2006;12(6):544-548. https://doi.org/10.1111/j.1524-4741.2006.00343.x

27. Mahner S, Schirrmacher S, Brenner $W$, et al. Comparison between positron emission tomography using 2-[fluorine-18]fluoro-2-deoxy-D-glucose, conventional imaging and computed tomography for staging of breast cancer. Ann Oncol. 2008;19(7):1249-1254. https://doi.org/10.1093/annonc/mdn057

28. Sadigh G, Applegate KE, Baumgarten DA. Comparative accuracy of intravenous contrast-enhanced $C T$ versus noncontrast CT plus intravenous contrast-enhanced $\mathrm{CT}$ in the detection and characterization of patients with hypervascular liver metastases: A critically appraised topic. Acad Radiol. 2014;21(1):113-125. https:// metastases: A critically appraised topic.
doi.org/10.1016/j.acra.2013.08.023

29. McCartan DP, Prichard RS, MacDermott RJ, et al. Role of bone scan in addition to CT in patients with breast cancer selected for systemic staging. Br J Surg. 2016;103(7):839-844. https://doi.org/10.1002/bjs.10124

30. Jambor I, Kuisma A, Ramadan $\mathrm{S}$, et al. Prospective evaluation of planar bone scintigraphy, SPECT, SPECT/CT, 18F-NaF PET/CT and whole body $1.5 \mathrm{~T} \mathrm{MRI}$, including DWI, for the detection of bone metastases in high risk breast and prostate cancer patients: SKELETA clinical trial. Acta Oncol. 2016;55(1):59-67. prostate cancer patients: SKELETA clinical trial. Act
https://doi.org/10.3109/0284186X.2015.1027411

31. Liu T, Cheng T, Xu W, Yan WL, Liu J, Yang HL. A meta-analysis of 18FDG-PET, MRI and bone scintigraphy for diagnosis of bone metastases in patients with breast cancer. Skeletal Radiol. 2010;40(5);523-531. https://doi.org/10.1007/s00256-010-0963-8

32. Manenti G, Cicciò C, Squillaci E, et al. Role of combined DWIBS/3D-CE-T1w whole-body MRI in tumor staging: Comparison with PET-CT. Eur J Radiol. 2012;81(8):1917-1925. https://doi.org/10.1016/j.ejrad.2011.08.005 
33. Paruthikunnan SM, Kadavigere R, Karegowda LH. Accuracy of whole-body DWI for metastases screening in a diverse group of malignancies: Comparison with conventional cross-sectional imaging and nuclear scintigraphy. Am J Roentgenol. 2017;209(3):477-490. https://doi.org/10.2214/AJR.17.17829

34. Regier M, Schwarz D, Henes FO, et al. Diffusion-weighted MR-imaging for the detection of pulmonary nodules at 1.5 Tesla: Intraindividual comparison with multidetector computed tomography. J Med Imaging Radiat Oncol. 2011;55(3):266-274. https://doi.org/10.1111/j.1754-9485.2011.02263.x

35. Cardoso F, Senkus E, Costa A, et al. 4th ESO-ESMO international consensus guidelines for advanced breast cancer (ABC 4). Ann Oncol. 2018;29(8):1634-1657. https://doi.org/10.1093/annonc/mdy192

36. Berney M, Manning A, Carter M, Sacchini V, Kell MR, Barry M. Systematic review and meta-analysis to determine the optimum staging modality for primary breast cancer. Int J Cancer Clin Res. 2015;2(4):1-4. https://doi.org/10.23937/2378$3419 / 2 / 4 / 1026$
37. Hong S, Li J, Wang S. 18FDG PET-CT for diagnosis of distant metastases in breast cancer patients. A meta-analysis. Surg Oncol. 2013;22(2):139-143. https://doi. org/10.1016/j.suronc.2013.03.001

38. Cardoso F, Kyriakides S, Ohno S, et al. Early breast cancer: ESMO Clinical Practice Guidelines for diagnosis, treatment and follow-up. Ann Oncol. 2019;30(8):1194-1220. https://doi.org/10.1093/annonc/mdz173

39. National Comprehensive Cancer Network. NCCN guidelines: Breast cancer version 3 [homepage on the Internet]. 2019 [cited 2019 Jul 12]. Available from: https://www2.tri kobe.org/nccn/guideline/breast/english/breast.pdf

40. National Institute for Health and Care Excellence. Advanced breast cancer: Diagnosis and treatment [homepage on the Internet]. 2009 [cited 2019 Jul 12]. 2009. Available from: https://www.nice.org.uk/guidance/cg81/resources/ advanced-breast-cancer-diagnosis-and-treatment-pdf-975683850181

41. Vorster M, Doruyter A, Brink A, et al. Appropriate indications for positron emission tomography/computed tomography, 2015. SAMJ. 2015;106(1):105-122. https:// doi.org/10.7196/SAMJ.2016.v106i1.1018 